\title{
Mães portadoras do HIV/Aids: percepções acerca da severidade da infecção*
}

\author{
HIV-POSITIVE MOTHERS: PERCEPTIONS ABOUT THE SEVERITY OF THE INFECTION
}

MADRES PORTADORAS DEL HIV/SIDA: PERCEPCIONES ACERCA DE LA SEVERIDAD DE LAINFECCIÓN

Lis Aparecida de Souza Neves', Elucir Gir"

\section{RESUMO}

A complexidade da aids envolve não somente o lado cognitivo do conhecimento, mas também os enciam o comportamento das pessoas. Este estudo teve como objetivo identificar as percepções das mães soropositivas para o HIV acerca da severidade da infecção. Estudo qualitativo em que foram entrevistadas 14 mães soroposi2004. Os dados foram interpretados utilizando-se o método da Análise de Conteúdo e o Modelo de Crenças em Saúde. As categorias que emanaram dos dados não pensar na doença e medo da morte, refletem a fase atual da epidemia em que os medicamentos anti-retrovirais transformaram a aids em uma doença crônica, ao mesmo tempo em que o medo é uma constante devido ao fato da associação entre aids e morte persistir nas representações populares. $\mathrm{O}$ conhecimento das percepções maternas acerca da doença pode proporcionar aos profissionais de saúde maior compreensão de seus comportamentos. fatores psicossociais que influtivas que tiveram filho no ano de

\section{ABSTRACT}

The complexity of AIDS involves not just the cognitive side of knowledge, but also the psychosocial factors that influence the behavior of individuals. The objective of this study was to identify the perceptions of HIV-positive mothers concerning the severity of the infection. This is a qualitative study for which were interviewed 14 seropositive mothers who bore a child in the year of 2004. To analyze the data the authors used the Analysis of Content and Health Belief Model. The categories that emerged from the data - not to think about the illness and fear of death - reflect the current phase of the epidemic, in which the introduction of medicines has turned AIDS into a chronic illness while fear is still present because the association between the disease and death persists in popular representations. Knowing mothers' perceptions concerning the illness may give health professionals better understanding of these women's behavior.

\section{RESUMEN}

La complejidad del sida envuelve no solamente el lado cognitivo del conocimiento, pero también los factores psicosociales que influencian el comportamiento de las personas. Este estudio tuvo como objetivo identificar las percepciones de las madres suero positivas para el HIV acerca de la severidad de la infección. Estudio cualitativo en que fueron entrevistadas 14 madres suero positivas que tuvieron hijo en el año de 2004. Los datos interpretados utilizándose el método de Análisis de Contenido y el Método de Creencias en Salud. Las categorías que emanaron de los datos no pensar en la enfermedad y miedo de la muerte, reflejan la fase actual de la epidemia en que los medicamentos anti-retrovirales transformaron el sida en una enfermedad crónica, al mismo tiempo en que el miedo es una constante debido al hecho de la asociación entre sida y muerte persistir en las representaciones populares. El conocimiento de las percepciones maternas acerca de la enfermedad puede proporcionar a los profesionales de salud mayor comprensión de sus comportamientos.

\section{DESCRIPTORES}

KEY WORDS

HIV.

Síndrome de Imunodeficiência Adquirida.

Atitude frente à saúde.

Saúde da mulher
HIV.

Acquired Immunodeficiency

Syndrome.

Attitude to health.

Women's health.
VIH.

Síndrome de Inmunodeficiencia Adquirida.

Actitud frente a la salud.

Salud de las mujeres.

\footnotetext{
Extraído da dissertação "Prevenção da transmissão vertical do HIV/Aids: compreendendo as crenças e percepções das mães soropositivas", Escola de Enfermagem de Ribeirão Preto, Universidade de São Paulo, 2005.

I Mestre em Enfermagem Fundamental. Enfermeira do Programa Municipal de DST/Aids de Ribeirão Preto, Ribeirão Preto, SP, Brasil. lisapneves@ yahoo.com.br

II Enfermeira. Professora Titular da Escola de Enfermagem de Ribeirão Preto, Universidade de São Paulo (EERP/USP), Ribeirão Preto, SP, Brasil. egir@eerp.usp.br
} 


\section{INTRODUÇÃO}

Os últimos dados apresentados pelo Ministério da Saúde nos mostram que a epidemia de aids no Brasil continua em patamares elevados, tendo atingido em 2003 a incidência de 18,4 casos por 100.000 habitantes. Nos homens há uma tendência de estabilização, sendo registrada uma taxa menor do que a de 1998. No entanto, o crescimento continua entre as mulheres, sendo que em 2003 ocorreu a maior taxa de incidência nesse grupo populacional: 14,1 casos por 100.000 mulheres $^{(1)}$.

A via sexual é a forma predominante de transmissão no Brasil, principalmente na população feminina. Se considerarmos que $85 \%$ das mulheres infectadas pelo HIV (Vírus da Imunodeficiência Humana) estão em idade fértil, tem-se o problema adicional da transmissão vertical do HIV, também denominada materno infantil, que representa a principal forma de disseminação desse vírus na população pediátrica.

É estimado que 15 a $30 \%$ das crianças nascidas de mães portadoras do HIV adquiram o vírus durante o período gestacional e perinatal. Entretanto, a combinação das intervenções recomendadas para profilaxia da transmissão vertical do HIV reduziu as taxas de transmissão para cifras inferiores a $1 \%$.

No caso da prevenção da transmissão vertical, é relevante que a mãe seja aderente a todos os procedimentos necessários para diminuir os riscos desta transmissão. Adesão é aceitação, concordância, e aderir, é $o$ ato de apoiar, de aceitar uma idéia ${ }^{(3)}$. A mãe só vai aderir ao tratamento preventivo, se estiver sensibilizada com a idéia de que a aids é uma doença grave e que a criança pode ser infectada.

Vários fatores têm sido associados com a adesão ao tratamento, entre eles os psicossociais, relacionados com a pessoa, seu perfil socioeconômico, sua escolaridade e suas crenças. As crenças e percepções parecem influenciar diretamente no comportamento e nas atitudes dos seres humanos.

Realizamos então um estudo buscando identificar as crenças das mães portadoras do HIV para compreender o comportamento delas em relação à adesão às medidas profiláticas da transmissão vertical. O referencial teórico utilizado foi o Modelo de Crenças em Saúde (MCS), composto das dimensões de susceptibilidade percebida, severidade percebida, benefícios e barreiras percebidas.

Este artigo é uma parte do referido estudo, e nele tivemos como objetivo identificar as percepções das mães soropositivas para o HIV acerca da severidade da infecção.

\section{OBJETIVOS}

Identificar as percepções das mães soropositivas para o HIV acerca da severidade da infecção.

\section{MÉTODO}

Trata-se de um estudo descritivo de natureza qualitativa. O referencial teórico utilizado é o Modelo de Crenças em Saúde ${ }^{(4)}$, visto que esse procura explicar a adoção de comportamentos preventivos e estabelecer relações entre o comportamento individual e algumas crenças individuais ${ }^{(5)}$.

As características preliminares do MCS consideram que para um indivíduo adotar medidas preventivas, ou seja, evitar doenças, ele necessariamente precisa acreditar em três aspectos: que ele é susceptível à doença; que a ocorrência da doença deverá acarretar pelo menos alterações moderadas em alguns componentes de sua vida; que a tomada de determinada ação deverá ser benéfica, reduzindo sua susceptibilidade à referida condição, diminuindo sua gravidade e desvinculando-a de barreiras mais importantes, tais como custo, conveniência, dor, embaraço ${ }^{(4)}$. O MCS é composto basicamente de 4 dimensões: susceptibilidade percebida, severidade percebida, benefícios percebidos e barreiras percebidas.

Neste artigo, enfocaremos a percepção de severidade que está relacionada ao estímulo emocional criado pelo pensamento acerca de um problema de saúde e às conseqüências que o indivíduo acredita que este poderia provocar em sua vida. Sentimentos relativos à severidade de se contrair uma doença ou deixá-la sem tratamento levariam o indivíduo a avaliar as consequeências clínicas e físicas resultantes, como dor, redução das funções físicas e mentais, temporária ou permanentemente, possíveis conseqüências sociais, como implicações no trabalho, vida familiar e/ou relações sociais, ou mesmo a morte ${ }^{(4)}$.

A população alvo do estudo constituiu-se de mulheres portadoras do HIV, cuja gravidez resultou em nascimento de criança viva no município de Ribeirão Preto no ano de 2004. Como critérios para inclusão no estudo consideramos: o parto ter ocorrido em Ribeirão Preto e ainda residir no município no momento da coleta de dados; estar em boas condições físicas e emocionais; o filho ter no mínimo 6 meses de vida e estar sob os cuidados da mãe; concordar em participar da investigação. A amostra final foi composta por 14 mulheres.

Para a coleta de dados, empregamos a técnica de entrevista semi-estruturada gravada na residência das mulheres e norteada pelo instrumento específico. Este instrumento 
era composto de duas partes sendo que a primeira parte continha alguns dados sociodemográficos para caracterização das mulheres. A segunda parte era norteada pela questão: quais as suas crenças e percepções a respeito do HIV/ aids e da possibilidade de transmití-lo para a criança?

No momento da visita, era realizada a leitura do termo de consentimento livre e esclarecido, como também lhe era assegurado o sigilo e a confidenciabilidade dos dados. Para garantir o anonimato das participantes, os nomes foram substituídos por nomes de flores. A coleta aconteceu no período de novembro de 2004 a janeiro de 2005.

Para análise dos dados utilizamos o método da Análise de Conteúdo ${ }^{(6)}$. Os conteúdos foram selecionados, codificados e inseridos em categorias e subcategorias.

O projeto foi apreciado pelo Secretário Municipal da Saúde de Ribeirão Preto e aprovado pelo Comitê de Ética em Pesquisa da Escola de Enfermagem de Ribeirão Preto - Universidade de São Paulo (Processo CEP n. 0403/2003).

\section{RESULTADOS}

A população estudada foi constituída por 14 mulheres soropositivas para o HIV, cujo parto ocorreu no município de Ribeirão Preto no ano de 2004; o intervalo de idade expresso pelo grupo variou de 15 a 37 anos.

Constatamos que uma das entrevistadas não é alfabetizada; 11 cursaram o Ensino Fundamental, uma concluiu o Ensino Médio, e uma possui curso superior completo. A renda familiar variou de zero a 6 salários mínimos, sendo que apenas 2 possuíam mais de 3 salários.

Outro dado que influencia o padrão social da família, é o número de filhos. Em nossa amostra, 6 mulheres possuíam mais de 3 filhos, sendo que 1 apresentava 13 filhos.

Quanto à forma de transmissão do HIV, 11 mulheres informaram ter sido infectadas através das relações sexuais com seus parceiros; 2 afirmaram não saberem como foram infectadas e uma o foi devido a transmissão vertical. Todas negaram uso de drogas injetáveis.

Com relação ao pré-natal, 2 participantes não o realizaram, mesmo já sabendo que eram portadoras do HIV; todas faziam o seguimento especializado da criança.

A partir da transcrição das entrevistas e após a leitura exaustiva das falas, apareceram conteúdos recorrentes e em alguns momentos até contraditórios, que foram inseridos nas dimensões do referencial teórico.

Na percepção da severidade da doença, foram incluídas duas categorias que emanaram da fala das entrevistadas: não pensar na doença e medo da morte.

\section{Não pensar na doença}

Na história da aids existem dois períodos bem delimitados: antes da década de 90, quando prevalecia a imagem da aids ligada à desesperança e morte; e após, com o uso dos medicamentos anti-retrovirais (ARVs). $\mathrm{O}$ advento dessa terapia em 1996 trouxe a perspectiva de que a aids passaria a ser uma enfermidade crônica, compatível com uma sobrevivência, até então inusitada e, sobretudo, com grande preservação da qualidade de vida. Esta perspectiva se confirmou em estudos que mostram que a sobrevida do paciente com aids aumentou significativamente após esse período, concomitante com a queda nas taxas de internação e mortalidade por aids no Brasil ${ }^{(7-8)}$.

Essa percepção é sentida pelas mulheres portadoras do HIV e que ainda não manifestaram sintomas, relegando a existência do vírus para segundo plano.

Como eu só tenho o vírus, não tem muito problema, só se machucar e contaminar outra pessoa ... (Gerânio).

Ela falou que eu só tenho HIV, e que não é pra eu pensar nisso. A gente fica mais aliviado (Flor do campo).

Você toma, abaixa a carga viral e continua vivendo normal, é crônico. Igual é como se fosse a minha sinusite, vem aquela dor de cabeça louca, eu corro, faço o tratamento, corrige e então eu quero esperar assim, que é uma coisa que não vai me matar (Jasmim).

Fui fazer o pré-natal, o médico me falou e me mandou para o HC. Eu fiquei muito triste né, mas a vida continua, eu não vou morrer de hoje para amanhã se eu me cuidar. Eu não entrei muito em desespero não (Orquídea).

Há 10 anos atrás não tinha recurso; hoje em dia tem o coquetel né. Eu não estou tomando agora, mas eu acho que depois que você que precisa tomar é uma doença que você tem que fazer o tratamento o tempo que tiver que viver (Violeta).

Elas sabem que têm o vírus, mas relutam em entrar em contato com essa realidade que além de ser dolorosa, impõe um novo direcionamento em suas vidas. Transparece assim, a complexidade contextual da aids, cheia de contradições e incoerências dos sentimentos do ser humano.

Pelo fato da aids ainda ser uma doença associada à morte, uma forma de sobreviver com o diagnóstico de ser portadora é relegar o HIV para segundo plano, não deixando que ele ocupe um espaço grande em suas vidas.

Ela falou que eu só tenho HIV e que não é pra eu pensar nisso não. A gente fica mais aliviado (Flor do campo).

O HIV é assim, tipo câncer, só que o câncer normalmente a pessoa tem tendência, não pega de outra pessoa. Eu prefiro não ficar tão preocupada, se não entro em depressão. Então eu prefiro não preocupar muito não, porque já tá aqui na minha cabeça, entendeu. Eu tenho que levar a minha vida (Margarida). 
A depressão é imediatamente relacionada ao pensar em excesso sobre uma situação, no caso a doença e está intimamente relacionado ao corpo, produzindo efeitos neste. Assim, este ato de pensar sobre a doença é identificado como a principal fonte de angústias individuais e é percebido, neste sentido, como um verdadeiro acelerador da mor$\mathrm{te}^{(9)}$. Esta percepção é muito clara na fala de Calêndula,

se eu colocar na cabeça que eu vou morrer, não adianta vai dar depressão e vou morrer mesmo.

Devemos nos esforçar para que a aids não seja tudo, mas apenas uma doença; o pensar sobre a doença não deve causar mais sofrimento em $\mathrm{si}^{(10)}$. O pensar excessivamente em aids é visto como uma forma de rendição à doença, como na fala de Jasmim:

\begin{abstract}
A gente chegou a sentar e conversar que eu não podia mudar. A gente ia acompanhar, só que não ia deixar isso interferir na nossa vida. Então é assim, a gente é normal como se não tivesse, quando dá o tempo de fazer os exames, a gente faz, se precisar tomar remédio a gente toma, mas sem nunca abaixarmos a cabeça para isso, nunca deixar que isso seja mais forte que a gente (Jasmim).
\end{abstract}

Essa rendição é veementemente recusada, tentando restabelecer a normalidade cotidiana e lutando pela vida.

Revendo novamente a fala de Violeta,

Eu não estou tomando agora, mas eu acho que depois que você que precisa tomar é uma doença que você tem que fazer o tratamento o tempo que tiver que viver (Violeta).

A frase o tempo que tiver que viver nos induz a refletir sobre o uso contínuo dos medicamentos que fizeram com que a aids passasse a ser considerada uma doença crônica: como está sendo a vida desses pacientes? Um dos aspectos que emergem é a questão da qualidade de vida a partir da descoberta de que se pode conviver com o HIV, mas em uso contínuo de medicamentos, que trazem o benefício de controlar a doença juntamente com as dificuldades dos efeitos colaterais:

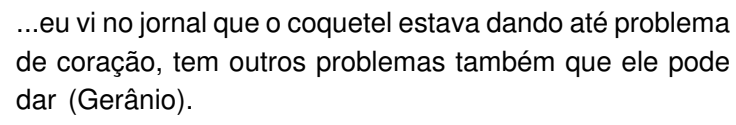

...às vezes o remédio mexe com outras coisas, eu tenho isso na minha cabeça, mexe com outras coisas e até prejudica (Flor do campo).

Além da própria dificuldade em manter o uso contínuo da medicação, os ARVs têm inúmeros efeitos adversos que causam uma diminuição na aderência ao tratamento. Em estudo sobre os fatores psicossociais que dificultam a adesão das mulheres portadoras do HIV aos cuidados de saúde ${ }^{(11)}$, é ressaltado o quão estigmatizante pode ser os efeitos colaterais do coquetel, principalmente a lipodistrofia. Com isso, a auto-imagem e o estado emocional do paciente são muito afetados, principalmente os do sexo feminino, diminuindo a sua auto-estima e o seu bem estar físico e conseqüentemente caindo a qualidade de vida.

O termo qualidade de vida é bastante abrangente, estando diretamente relacionado às experiências individuais, num dado momento dentro de um contexto sociocultural ${ }^{(12)}$. Se considerarmos a redução dos índices de mortalidade e internação, a qualidade de vida dos portadores de HIV/aids melhorou muito ${ }^{(13)}$. Porém, o uso sistemático dos ARVs tem mostrado que eles apresentam efeitos adversos que interferem diretamente no bem estar bio-psico-social e conseqüentemente, na qualidade de vida do paciente.

$\mathrm{O}$ alto custo dos medicamentos e os inúmeros efeitos colaterais têm direcionado investigações sobre o impacto dessa terapêutica na qualidade de vida. Verificar a qualidade de vida é importante para direcionar as estratégias de tratamento, de distribuição de recursos e os programas de saúde, os quais, por sua vez, podem privilegiar não só os aspectos físicos da clientela, mas também aqueles relacionados às dimensões psíquicas e sociais, possibilitando à equipe de saúde planejar o cuidado integral ${ }^{(14)}$.

Se com as medicações surge a questão da qualidade de vida, por outro lado, sem um acompanhamento especializado no que diz respeito à infecção pelo HIV, as mulheres podem estar se colocando em um risco ainda maior. A adesão ao tratamento e a vida é fundamental para o alcance de melhores resultados. Para que isso seja alcançado a cliente tem que estar ciente da severidade da doença. Entre as nossas entrevistadas, 4 mulheres ainda não tinham iniciado o tratamento após o parto.

\section{Ah, eu não vou em médico não, não tenho nada, nunca nem tomei remédio, e eu nunca vi ninguém com aids (Tulipa).}

A inexistência de sintomas concretos tais como dor, febre e outras alterações perceptíveis, pode resultar em uma descrença com relação à existência do HIV, estimulando um comportamento inapropriado à saúde e não considerando a severidade da doença.

Para uma parcela significativa da população, só se toma alguma providência depois do fato instalado, ou seja, depois da manifestação de algum sintoma. A presença de idéias populares, tais como as pessoas só acreditarão na doença quando acontecer com elas, sinaliza que a população ainda não se sente suficientemente em risco de contrair a doença ${ }^{(15)}$. No caso da situação de já ser portadora do HIV, a presença do vírus não tem um significado concreto, pois ainda não há sintomas aparentes que comprovem a sua existência.

A observação da epidemia de aids tem mostrado que os comportamentos individuais desempenham papel crucial na 
transmissão do HIV e que as estratégias de prevenção de seu crescimento devem levar esse fator em consideração.

Outro aspecto a ser considerado é a crença de que, se evitarem comportamentos comumente associados a doenças em geral, podem estar se protegendo de desenvolver a aids.

... assim nunca manifestou coisa em mim, uma que eu me cuido, não bebo, não fico no sereno, não uso droga, essas coisas assim, do meu jeito, mas está indo (Camomila).

O imaginário de estar se cuidando deixando de adotar alguns comportamentos danosos à saúde é suficiente para evitar a busca pelo tratamento adequado. Porém, essa mesma entrevistada não deixa de levar sua filha ao ambulatório, para evitar que ela se contamine. O papel de cuidadora que as mulheres desempenham na sociedade faz com que, para a maioria delas, a primeira responsabilidade seja com a saúde de seus filhos e até com outras pessoas da família, e, por isso, muitas vezes não se percebam sob risco. Ela negligencia os cuidados adequados com a própria saúde, porém faz tudo para cuidar da filha e evitar que venha a se infectar.

\section{Medo da morte}

Concomitante ao fato de não pensar na doença considerando-a como um mal menor e novamente realçando a complexidade da aids e suas contradições, o medo da morte e a depressão, que algumas tentam fugir, podem aparecer a essas mulheres até como uma reação normal, na medida em que manifestam os sentimentos de perda decorrentes da doença:

Eu vi gente muito mal no hospital, se não se cuidar, acabou (Lírio).

Acho que se a criança nasce com o vírus ela tem pouca chance de viver (Violeta).

Eu sei que a aids mata, que HIV mata e dá muita doença, $e$ que se você não se proteger, se você sair com homem vai passar aids para os outros. Se você por na cabeça, vai morrer mais rápido (Hortência).

A fala de Hortência revela que a presença do HIV trouxe a certeza da morte, a ansiedade e o medo de morrer, medo esse que é mais acentuado quando se pensa na possibilidade da criança ficar infectada e doente.

Apesar da evolução no tratamento da aids, que aumentou a sobrevida do paciente e a transformou em uma doença crônica, nas representações populares a associação entre aids e morte é muito presente. A associação que as mulheres infectadas fazem com a morte se manifesta principalmente na revelação do diagnóstico ${ }^{(9)}$. Posteriormente, quando elas vão entrando em contato com os profissionais de saúde e outras pessoas na mesma situação, associado à ausência de sintomas da doença, elas consideram que a morte não é tão imediata como pensavam. Dessa forma, a invisibilidade da doença permite também a invisibilidade da própria morte ${ }^{(9)}$.
A percepção de morte também se manifesta de maneira desigual nos diferentes grupos sociais. A ameaça concreta de morte é muito mais presente nas camadas sociais mais desfavorecidas da população, que convivem expostos às situações de violência quotidiana e a condições precárias de vida. Para a maioria das mulheres participantes de nosso estudo, que está inserida nestas camadas, a presença da morte independe da doença. A aids é apenas mais uma ameaça, um risco que vem se juntar aos demais.

...eu penso assim, um dia todo mundo vai morrer, você sai na rua um carro te atropela, leva uma bala perdida, a vida é assim, está nas mãos de Deus, eu penso assim (Calêndula).

Eu estou me virando aqui, faz 15 dias que eu voltei para as ruas pra poder pagar a babá e dar as frutinhas pra ela (bebê). É muito puxado, tem dia que não faz quase nada, os homens tem medo de vir aqui porque o lugar está perigoso, o pessoal está roubando muito; eu tenho que ficar porque está valendo a pena, minha filha está linda! (Camomila).

A realidade das mulheres que vivem em situações menos favorecidas é de luta constante pela sobrevivência, muitas vezes mobilizando sentimentos de apego a uma crença religiosa. Esse apego também pode se transformar em uma alternativa de enfrentamento da doença:

\section{Eu entreguei nas mãos de Deus, ele é que vai me dar essa resposta (Camomila).}

\section{...a saúde dele que está em jogo, mesmo que eu sabia que ele era negativo, mas a gente tem que fazer a parte da gente,que nem Jesus fala, faz a sua parte que eu te ajuda- rei (Calêndula).}

A religião surge como apoio, representando uma importante rede de suporte emocional. A fé no divino é uma forma de explicar o mundo, de superar e suportar o cotidiano da existência, associando-o à esperança ${ }^{(16)}$.

A fé na cura se assenta na crença de um poder superior, que lhes dá esperança, conforme observamos nas falas:

...quem sabe mais pra frente, Deus prepara um remédio pra curar, mas eu não quero pensar nisso agora não (Flor do campo).

Eu fiquei 9 meses indo naquela igreja da catedral e pedia ai meu Deus, não faz isso com meu filho não; a gente não pode perder a esperança, tem que levar o menininho e acreditar em Deus (Hortência).

A religião é um sistema de símbolos que atua para estabelecer poderosas e duradouras motivações nos homens, através de conceitos de ordem de existência geral, e vestindo estas concepções com tal aura de fatalidade que as motivações parecem singularmente realistas ${ }^{(17)}$. 
Muitos estudos abordam as diferentes estratégias pelas quais as religiões reinterpretam a experiência da doença e modificam a maneira pela qual o doente e o meio social definem o problema.

As mulheres se beneficiam de sua crença religiosa, visto que esta se torna fonte de esperança, uma forma de enfrentamento e alívio para o sofrimento, medo e angústia ${ }^{(18)}$.

Nesse caso, a percepção de severidade é tão presente que a crença religiosa é uma forma de suportar as angústias impostas pela doença.

\section{CONSIDERAÇÕES FINAIS}

Os avanços alcançados com a terapia medicamentosa, aliada a outros procedimentos, reduziram consideravelmente a taxa de transmissão materno infantil. Porém, para alcançar estes resultados as mães têm que estar estimuladas a realizarem os procedimentos preconizados pelos profissionais de saúde.

A percepção de severidade pode ser avaliada pelo grau de perturbação emocional criado ao pensar na doença e pelos tipos de conseqüências que ela pode acarretar.

\section{REFERÊNCIAS}

1. Brasil. Ministério da Saúde. Guia de tratamento clínico da infecção pelo HIV em crianças. Brasília; 2004.

2. Brasil. Ministério da Saúde. Guia de tratamento: recomendações para a profilaxia da transmissão vertical do HIV e terapia antiretroviral em gestantes. $2^{\mathrm{a}}$ ed. Brasília; 2003.

3. Houaiss A. Minidicionário da língua portuguesa. Rio de Janeiro: Objetiva; 2001.

4. Rosenstock IM. The health belief model: explaining health behavior through expectancies. In: Glanz K. Health behavior and health education: theory, research and practice. San Francisco: Jossey-Bass; 1990. p. 39-62.

5. Dela Coleta MF. Modelo de crenças em saúde. In: Dela Coleta MF, organizadora. Modelos para pesquisa e modificação de comportamentos de saúde. Taubaté: Cabral; 2004. p. 27-61.

6. Bardin L. Análise de conteúdo. Lisboa: Edições 70; 1995.

7. Marins JRP, Jamal LF, Chen SY, Barros MB, Hudes ES, Barbosa AA, et al. Dramatic improvement in survival among adult Brazilian AIDS patients. AIDS. 2003;17(11):1675-82.

8. Matida LH, Marcopito LF. Aumento do tempo de sobrevida das crianças com AIDS - Brasil. Bol Epidemiol AIDS. 2002;15(1):49-56.

9. Knauth D. Psicoterapia, depressão e morte no contexto da AIDS. In: Alves PC, Rabelo MC. Antropologia em saúde: traçando identidades e explorando fronteiras. Rio de Janeiro: FIOCRUZ; 1998. p. 139-56.

10. Ruiz JS. A AIDS e suas representações: possibilidades de elaboração [dissertação]. São Paulo: Pontifícia Universidade Católica de São Paulo; 1999.
O pensar em excesso sobre a doença é imediatamente relacionado à depressão, produzindo efeitos no corpo e sendo considerado um acelerador do processo de morte. Render-se à aids, deixar que ela seja mais forte que o próprio indivíduo é uma atitude recusada no sentido de lutar pela vida e tentar restabelecer a normalidade cotidiana.

Por outro lado, a severidade pode ser subestimada pelo fato de ainda não manifestar sintomas, sendo influenciada pelo contexto sóciocultural em que a mulher está inserida.

Concomitante ao fato de tentar relegar o HIV para segundo plano, o medo pode aparecer até como uma reação normal na medida em que manifesta os sentimentos de per$d a$ decorrentes da doença. A associação entre aids e morte ainda é muito presente nas representações populares, se manifestando na mulher infectada principalmente na revelação do diagnóstico.

Os profissionais têm que estar sempre preparados em manter uma escuta ativa frente às mulheres soropositivas para identificar se o fato de não pensar no HIV é uma atitude positiva, como uma forma de sobrevivência de alguém que conhece a severidade da doença, ou negativa, devido a descrença naquilo que não é concreto e, portanto, não deve ser severo.

11. Tunala L, Paiva VSF, Ventura-Felipe E, Santos TLL, Santos N, Hearst N. Fatores psicossociais que dificultam a adesão das mulheres portadoras do HIV aos cuidados de saúde. In: Teixeira PR, Paiva V, Shimma E. Tá difícil de engolir? Experiências de adesão ao tratamento anti-retroviral em São Paulo. São Paulo: Nepaids; 2000. p. 79-114.

12. Minayo MCS, Hartz ZMA, Buss PM. Qualidade de vida e saúde: um debate necessário. Ciênc Saúde Coletiva. 2000;5(1):7-18.

13. Guimarães MS, Raxack JC. A questão da adesão: os desafios impostos pela AIDS no Brasil e as respostas do governo, de pessoas e da sociedade. Impulso Rev Ciênc Soc Hum. 2002;13(32):69-89.

14. Canini SRMS, Reis RB, Pereira LA, Gir E, Pelá NTR. Qualidade de vida de indivíduos com HIV/AIDS: uma revisão de literatura. Rev Lat Am Enferm. 2004;12(6):940-5.

15. Lefèvre F, Lefèvre AMC, Scandar SAS, Yassumaro S. Representações sociais sobre relações entre vasos de plantas e o vetor da dengue. Rev Saúde Pública. 2004;38(3):405-14.

16. Santos ALD, Rosenburg CP, Buralli KO. Histórias de perdas fetais contadas por mulheres: estudo de análise qualitativa. Rev Saúde Pública. 2004;38(2):268-76.

17. Gertz C. A interpretação das culturas. Rio de Janeiro: Zahar; 1989.

18. Saldanha AAW. Vulnerabilidade e construções de enfrentamento da soropositividade ao HIV por mulheres infectadas em relacionamento estável [doutorado]. Ribeirão Preto: Faculdade de Filosofia Ciências e Letras de Ribeirão Preto, Universidade de São Paulo; 2003. 